\title{
Contribuições do Design de Serviços às fragilidades da Educação Pública em contexto de ensino remoto por conta da Pandemia por COVID-19
}

\author{
Contributions of Service Design to Public Education weaknesses in the \\ context of remote education due to the Pandemic by COVID-19
}

Justine Noronha Hack, Raquel Leal Cunha Cruz Pereira, Bianca Maria Rêgo Martins

design de serviços, ensino-aprendizagem, educação pública; pandemia; design de informação;

\begin{abstract}
Este artigo tem o propósito de descrever e analisar os processos projetuais e as ferramentas de design utilizadas em estratégias de intervenção propostas pelos estudantes de graduação do $4^{\circ}$ período, do curso de Design da Escola Superior de Desenho Industrial (ESDI) da Universidade do Estado do Rio de Janeiro (UERJ), na disciplina Design de Serviços. O trabalho foi desenvolvido remotamente em parceria com 5 professoras da Rede Pública de Educação que fazem parte do grupo de estudos Design \& Escola que pertence ao Deseduca Lab - Laboratório de Design e Educação ESDI/UERJ, e teve como base as dificuldades e demandas relatadas por elas, com enfoque na circunstância de ensino-aprendizagem a distância. Assim, destaca-se o potencial do Design de Informação na visualização e análise de dados interdisciplinares e o Design de Serviços como contribuinte para desdobramento de abordagens pontuais às problemáticas e gargalos de situações complexas da Educação, que envolvem diferentes agentes e realidades. As intervenções propostas foram acompanhadas e validadas pelas professoras e, tendo alcançado resultados satisfatórios, estão aptas a serem postas em prática.
\end{abstract}

service design, teaching-learning, public education, pandemic; information design;

This article aims to describe and analyse the project process and design tools used in intervention strategies proposed by undergraduate students of the 4th period, from the Design course at the School of Industrial Design (ESDI) of the State University of Rio de Janeiro (UERJ), in the discipline "Service Design". This work was carried out remotely in partnership with 5 Public School's teachers who are part of the "Design and School" study group that belongs to "Deseduca lab" - Design and Education laboratory ESDI/UERJ - and was based on the difficulties and demands reported by them, with focus on the distance teaching-learning circumstances. Therefore, it highlights the potential of Information Design in the visualization and analysis of interdisciplinary data and Service Design as a contributor to the deployment of specific approaches to the problems and bottlenecks of complex situations in Education, involving different agents and realities. The proposed interventions were followed and validated by the teachers and, having achieved the satisfactory results, they can be leveraged in practical cases.

\section{Introdução}

Em 2019, em Wuhan, na China, eclodiu um novo vírus, desconhecido para a humanidade, que deixou o mundo todo em alerta. O Sars-Cov-2, que causa a COVID-19, trouxe uma nova

Anais do $10^{\circ} \mathrm{CIDI}$ e $10^{\circ} \mathrm{CONGIC}$

Kelli C.A.S. Smythe, Rafael de Castro Andrade (orgs.)

Sociedade Brasileira de Design da Informação - SBDI

Curitiba | Brasil | 2021
Proceedings of the $10^{\text {th }} \mathrm{CIDI}$ and $10^{\text {th }}$ CONGIC

Kelli C.A.S. Smythe, Rafael de Castro Andrade (orgs.)

Sociedade Brasileira de Design da Informação - SBDI Curitiba | Brazil | 2021 
realidade para o Brasil e, a partir de 13 de março de 2020, foi decretada a quarentena. Com essa medida, comércios, escolas e empresas tiveram que fechar temporariamente para que fosse possível conter o avanço do vírus, o que fez com que todos precisassem se reinventar. Trabalhos presenciais passaram a ser home-office (em relação à parcela da população com esse privilégio) e escolas e faculdades passaram a ter aulas online (síncronas ou assíncronas).

Com isso, professores que nunca deram aula à distância ou gravaram uma vídeoaula, tiveram que improvisar e aprender várias tecnologias do zero, além de didáticas de ensinoaprendizagem remotos e plataformas diversas adotadas pelas escolas. Sem mencionar a dificuldade conexão com os alunos por meio de uma tela, ou da dificuldade de boa parte da população brasileira de ter acesso à internet e a computadores.

A princípio, acreditou-se que esse "novo normal" duraria alguns meses. As medidas que estavam sendo tomadas pareciam ser temporárias. Afirmativa que se tornou falsa, pois mais de um ano após o primeiro decreto de quarentena, os números de mortes ainda estavam altíssimos e a pandemia estava longe de ser controlada no Brasil, como mostra a notícia a seguir, de abril de 2021: "Covid-19 já matou mais brasileiros em 4 meses de 2021 do que em todo ano de 2020" (G1, 25/04/2021).

Diante disso, alunos de escolas particulares puderam manter seus estudos, mesmo que online (Pimentel, 2020), enquanto alunos de escola pública, em sua maioria, estavam sem acesso às aulas, seja por falta de internet, porque as escolas estão fechadas, ou por inúmeros outros motivos que mostram a gritante desigualdade social que se intensificou no Brasil. (ENSP/Fiocruz, 2020).

A partir deste contexto, importantes estudos sobre a educação em tempos pandêmicos estão sendo feitos.

Este artigo é um relato de vivência da disciplina Design de Serviços, da graduação em Design da Esdi/UERJ, que descreve como foi praticado com os alunos o pensamento projetual e a visualização de dados, focados em resolução/abordagem de problemas reais e complexos da Educação, que teve como base um projeto de pesquisa e extensão do grupo de estudos Design \& Escola, pertencente ao Laboratório Design e Educação - DesEduca Lab, da mesma instituição.

\section{O grupo de estudos Design \& Escola}

Criado em 2019, o grupo de estudos Design \& Escola ESDI/UERJ visa investigar processos de Design em estratégias de ensino-aprendizagem, em redes educativas formais ou informais, explorando os usos do pensamento projetual em atividades integradoras de conhecimentos, procedimentos e afetos. Até o momento, faziam parte desse grupo graduandos, mestrandos e doutorandos na área de Design e Educação (seja voltado para o universo escolar, universitário ou formação de professores) e professoras da rede básica de educação de diferentes partes do Brasil - que estudaram ou não Design. A partir das experiências dessas professoras, de notícias jornalísticas e de artigos, pôde-se entender um pouco mais sobre a realidade e as dificuldades da educação pública em tempos pandêmicos. 
Surgiu assim, a ideia de um trabalho em parceria entre alunos da disciplina de Design e Serviços da ESDI com essas professoras, uma vez que entende-se que o Design é, em sua essência, resolução de problemas complexos (Cardoso, 2011, p. 243) e por isso, seria possível utilizá-lo para buscar possíveis soluções para as dificuldades enfrentadas por essas professoras e seus alunos no ambiente remoto, neste momento de pandemia.

\section{Metodologia}

A disciplina de Design e Serviços é a integração de duas disciplinas do currículo da ESDI: Design de Serviços 1 + Métodos e Ferramentas em Gestão de Serviços 2 e tem como objetivo trabalhar em parceria utilizando ferramentas práticas do Design.

No período de 2021.1, portanto, o projeto proposto por esta disciplina foi desenvolver uma abordagem propositiva de usos de sistemas de serviços para o contexto de uma turma do ensino público (desde educação infantil até ensino médio e $E J A^{1}$ ) tendo como cenário a Educação Remota por conta da pandemia por COVID-19.

A turma foi dividida em 7 grupos de 5 alunos que, a partir do tema proposto e de conversas com as parceiras, escolheu um caminho para trabalhar. $O$ projeto foi dividido em 3 entregas principais e 1 entrega final do projeto completo (com relatório técnico e vídeo), além de apresentações semanais a respeito do processo.

Sua duração foi programada para 13 semanas, a contar do primeiro dia de aula. Cada aula síncrona, feita pelo Google Meet tinha a duração de 3 horas, sendo as duas primeiras horas de apresentação e orientação sobre o andamento dos projetos (com um total de 15 minutos para cada grupo) e a última parte de novos conhecimentos, no qual eram apresentadas novas ferramentas para a prática do Design de Serviço. As entregas eram feitas às segundas-feiras, por meio assíncrono no Classroom, para que os professores tivessem tempo de ler os relatórios.

É importante ressaltar que todo processo foi feito por meio de aulas e encontros online, uma vez que não havia possibilidade de encontros presenciais. Além do Google Meet e do Classroom, citados anteriormente, também foi utilizada a plataforma Discord (eleita pela turma como a ferramenta mais oportuna a todos) como forma de interação e comunicação, sendo possível, então, acompanhar as discussões de todos os grupos simultaneamente. Através destas ferramentas e de uma escuta atenta, buscou-se dar voz e vez igualmente a todos, como forma de manter uma dinâmica mais produtiva, que atendesse às expectativas da maioria, principalmente levando em consideração o difícil momento vivido. Além disso, foi determinado que $20 \%$ da nota total fosse por meio de uma autoavaliação.

\footnotetext{
${ }^{1}$ Educação de Jovens e Adultos
} 


\section{Resultados/discussões}

As aulas começaram no dia 24 de fevereiro de 2021, com a apresentação da disciplina, das metodologias e dos vídeos relatos das professoras parceiras, nos quais os alunos precisavam basear suas pesquisas. Para a gravação desses vídeos, as professoras receberam a proposta da disciplina e um curto roteiro com algumas perguntas para orientar em seus relatos:

1. Breve biografia: o que te levou a ser professora?

2. Onde trabalha? Detalhes da escola (infraestrutura, tecnologia, como é a sala de aula...).

3. Fale sobre seus alunos (segmento e ano, idade, perfil, comportamentos...).

4. Fale sobre os principais problemas/desafios do dia a dia (pode ser apenas um ou você pode detalhar alguns).

6. Conte qual foi a maior mudança que você sentiu ao começar a dar aula por meio remoto.

7. Se puder, envie materiais adicionais (fotos, reportagens, etc.).

\section{Etapa 01}

A partir da apresentação dos vídeos, deu-se início à primeira etapa do projeto, que consistiu em pesquisas acerca do tema e na análise desses dados, finalizando (ENTREGA 01) com a definição da(s) oportunidade(s) de projeto - frase que conta um contexto que envolve pessoas, objetos, lugares e ações; questão do projeto; situação indesejada; problema de pesquisa. Esta etapa teve duração de 4 semanas, a contar do primeiro dia de aula até a entrega dos resultados. Os estudantes focaram suas pesquisas nos assuntos propostos pelas professoras nos quais tiveram mais afinidade.

Para esta etapa foram apresentadas ferramentas (1) de gestão e organização - que têm os objetivos de gerir e planejar o projeto, organizar informações, ter uma visão do projeto como um todo, alinhamento de equipe e compartilhamento de achados e responsabilidades; (2) de pesquisa em Design - que têm o objetivo de se preparar para a pesquisa, definir objetivos e fontes, entender informações que já existem sobre o tema, entender melhor o público pesquisado e os atores envolvidos, sistematizar e analisar a pesquisa de modo visual, identificar padrões e compartilhar a pesquisa; e (3) de visualização e síntese de dados com o objetivo de registrar de forma organizada os insights, comunicar o aprendizado do projeto, identificar pontos de aprofundamento, sintetizar a pesquisa direcionando-a a perspectivas relevantes e apontar para o objetivo do projeto.

A entrega foi uma apresentação em slides com uma síntese da pesquisa e a frase de oportunidade, que foi enviada para os professores 2 dias antes da aula síncrona. Dessa forma, os professores puderam avaliar a capacidade de sintetizar as informações e o uso das ferramentas utilizadas em cada sub-etapa. Essas apresentações foram avaliadas de acordo com os seguintes critérios: Diversidade de informação, profundidade de pesquisa, análise do 
material pesquisado, apreciação crítica, síntese gráfica, elaboração das frases de oportunidade (quem, o que, porque, quando e como) e viabilidade das oportunidades.

Cada grupo utilizou diversas ferramentas de acordo com o que julgavam ser mais pertinente aos seus projetos. É interessante observar que, mesmo que utilizassem as mesmas ferramentas, os resultados eram sempre diferentes, como pode ser visto nos exemplos abaixo, referente aos grupos 4 e 6 .

O grupo 4 deu início ao projeto dedicando-se à revisão dos depoimentos das professoras e fizeram anotações individuais do que observaram, além de uma pesquisa para entender melhor o contexto do ensino público na pandemia - ainda que de forma generativa - e entrevistas com 4 responsáveis de alunos para coletar artefatos de etnografia. Em uma reunião, analisaram essas informações e utilizaram a ferramenta Trello $^{2}$ (Figura 1) para organizá-las. Assim, realizaram um exercício de certezas, suposições e dúvidas (CSD), organizaram informações soltas e agruparam em assuntos que possuíam comprovações, assuntos que não tinham completa certeza e informações que poderiam gerar questionamentos e inquéritos generativos - que necessitam estudar e descobrir. Dessa forma, conseguiram pensar criticamente e de forma estrutural sobre os assuntos que foram surgindo no processo de pesquisa, com o objetivo de gerar mais possibilidades de caminhos para seguir.

Figura 1: CSD utilizando Trello. Fonte: Imagem retirada da apresentação do grupo 4.

\begin{tabular}{|c|c|c|c|}
\hline Olá & C. Certezas & S-Suposiçžes & D. Dúvidas \\
\hline $\begin{array}{l}\text { Nosso objetivo é entender } \\
\text { melhor o contexto do ensino } \\
\text { público, partindo da visāo } \\
\text { dessas professoras, } \\
\text { principalmente no que tange } \\
\text { aos impactos da pandemia }\end{array}$ & $\begin{array}{l}\text { A falta de financiamento è uma } \\
\text { realidade presente e impacta } \\
\text { diretamente na qualidade do ensino. } \\
\text { (-) }\end{array}$ & $\begin{array}{l}\text { As professoras de ensino público tem } \\
\text { que abarcar muitas } \\
\text { responsabilidades adicionais. } \\
\text { resolvendo problemas fora do eixo } \\
\text { ensino. Nas vezes que esses }\end{array}$ & $\begin{array}{l}\text { Quais problemas foram agravados ou } \\
\text { revelados pela pandemia? } \\
\text { (-) }\end{array}$ \\
\hline $\begin{array}{l}\text { Pro CSD, a parada aqui é só revisitar } \\
\text { as suas anotaçōes de percepçōes dos } \\
\text { depoimentos e pensar em que cada } \\
\text { coisa que vocé escreveu te provoca: }\end{array}$ & $\begin{array}{l}\text { Nảo existem parâmetros de } \\
\text { comparação da situaçảo remota em } \\
\text { tempos pandêmicos. } \\
\text { ๑) }\end{array}$ & $\begin{array}{l}\text { recursos elas tiram do próprio bolso. } \\
\text { Os alunos carecem de apoio } \\
\text { psicológico. }\end{array}$ & $\begin{array}{l}\text { Como prender a atençăo e engajar } \\
\text { os alunos? } \\
\text { ๑) }\end{array}$ \\
\hline $\begin{array}{l}\text { Se remeter a uma realidade } \\
\text { inalienável sobre o tema, vocé coloca } \\
\text { na coluna de CERTEZAS. Ex: Muitas } \\
\text { escolas públicas tem problemas de } \\
\text { financiamento }\end{array}$ & $\begin{array}{l}\text { Os professores enfrentam sérios } \\
\text { problemas com engajamento e } \\
\text { interaçăo no ensino remoto. }\end{array}$ & $\begin{array}{l}\text { A } 1 \text { ( }) \\
\text { Muitos alunos enfrentaram } \\
\text { dificuldades financeiras dentro de }\end{array}$ & $\begin{array}{l}\text { O que podemos tentar entender } \\
\text { sobre o estado mental das } \\
\text { professoras? }\end{array}$ \\
\hline 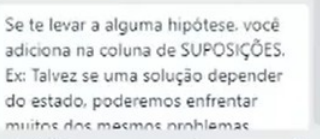 & $\begin{array}{l}\text { Alunos do EJA necessitam de } \\
\text { contextualizaç̧̃o no ensino e năo }\end{array}$ & $\begin{array}{l}\text { casa. Alguns começaram a trabalhar } \\
\text { em horário escolar por conta disso. } \\
\text { A1 - }\end{array}$ & $\begin{array}{l}\text { Os problemas com engajamento ja } \\
\text { existiam no ensino presencial? Como } \\
\text { se manifestavam? } \\
\text { () }\end{array}$ \\
\hline + Adicionar outro cartăo & + Adicionar outro cartâo & + Adicionar outro cartào & + Adicionar outro cartăo \\
\hline
\end{tabular}

Tal exercício possibilitou ao grupo ter uma visão mais ampla do projeto e retirar pontos centrais para futuramente entrar na pesquisa $D^{2} s k^{3}$. Assim, para dar sequência à pesquisa, definiram um panorama de acontecimentos de antes e depois da pandemia, o que facilitou a estruturação de conhecimentos que possuíam diversas ramificações. Utilizaram também o GoogleDocs, para uma escrita mais detalhada e registro de links externos, unindo referências

\footnotetext{
${ }^{2} \mathrm{O}$ Trello é uma ferramenta de gerenciamento de projetos em listas, com um design versátil e que pode ser ajustado de acordo com as necessidades do usuário.

${ }^{3}$ Pesquisa exploratória que utiliza informações já publicadas e disponíveis.
} 
de informações quantitativas, com o objetivo de entender mais sobre os cenários atuais em larga escala. Então, para criar relações entre as áreas estudadas e facilitar o entendimento sobre as informações, fizeram um mapa mental ${ }^{4}$ utilizando estratégias gráficas de cor, conexões e agrupamentos em comum.

Figura 2: Ferramenta de mapa mental em papel (em cima) e digital (abaixo). Fonte: Imagem retirada da apresentação do grupo 4.
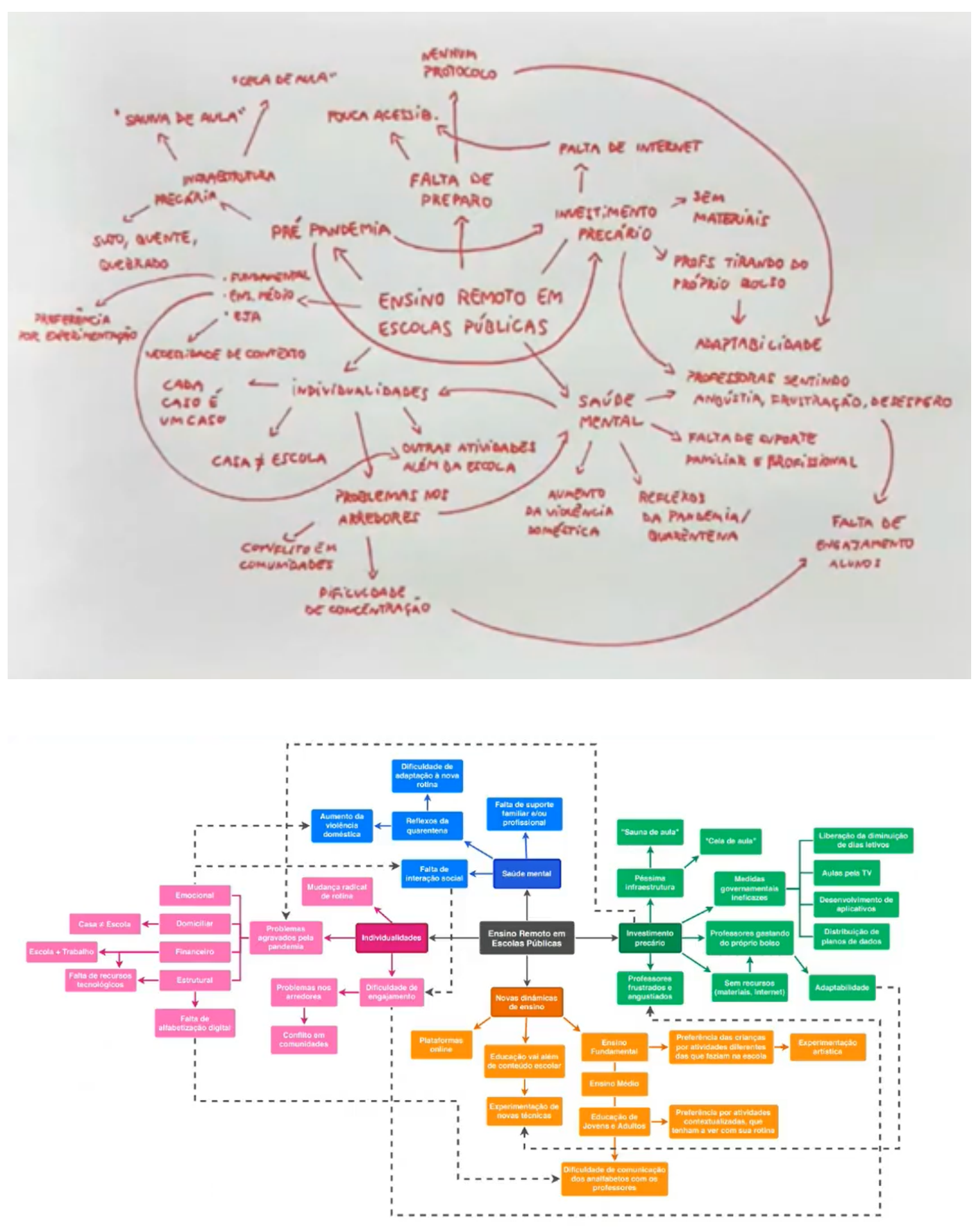

\footnotetext{
${ }^{4}$ Ferramenta de organização de ideias, em formato de diagrama, sistematizando e gerindo informações, de forma a facilitar o entendimento das principais questões e interconexões entre as mesmas (Buzan, 2002).
} 
Para desenvolver a pesquisa Desk, o grupo começou a usar a ferramenta Miro ${ }^{5}$, fragmentando as informações em onze quadrantes a serem trabalhados de acordo com o interesse de cada integrante do grupo. Nessas áreas, recolheram diversas notícias, dados, materiais e ferramentas que ajudaram a criar um mapa de acontecimentos e continuaram aplicando a técnica de CSD para sanar questões que eram dúvidas e levantar futuros gargalos para o projeto. Assim, abriram mais o campo de pesquisa em um âmbito nacional e político, focando em um levantamento de pesquisas gerais.

Figura 3: Pesquisa Desk utilizando a plataforma Miro. Fonte: Imagem retirada da apresentação do grupo 4.
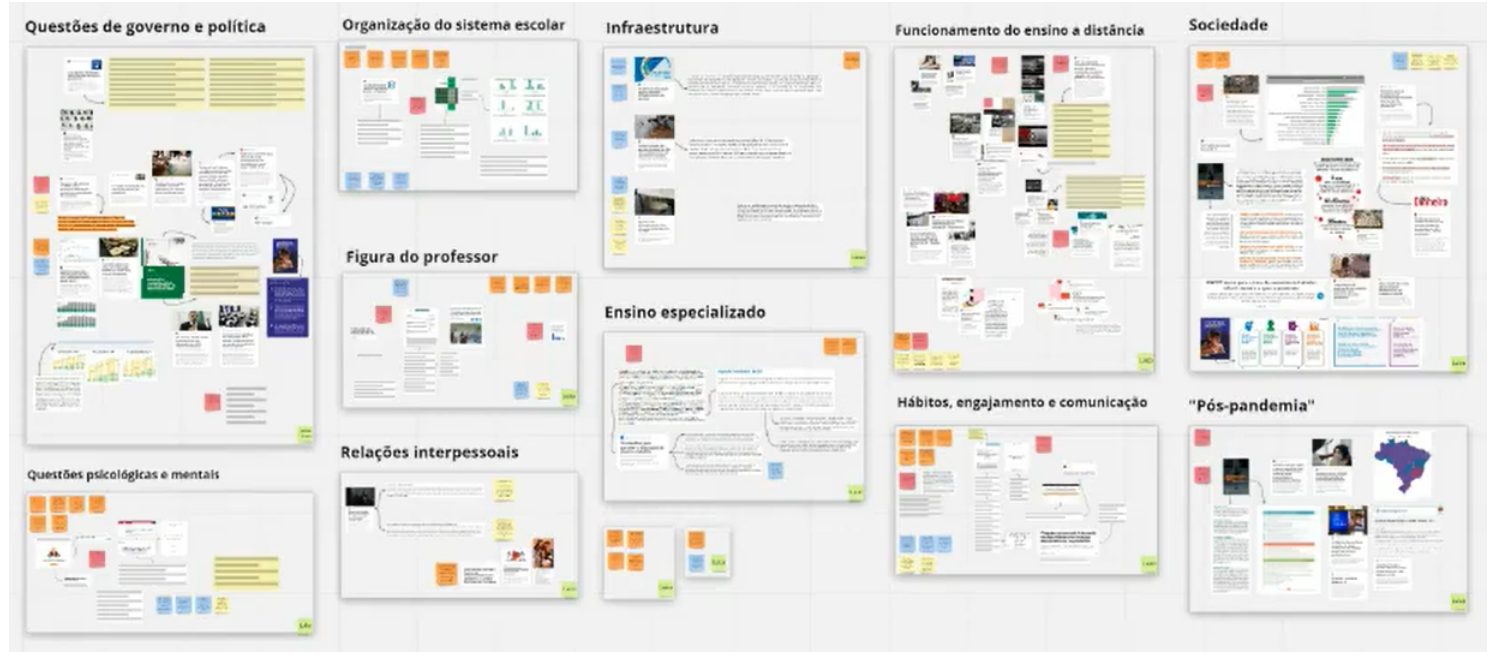

Para a ENTREGA 01, o grupo 4 fez uma síntese visual através de gráficos coloridos com dados quantitativos e notícias para embasar a pesquisa feita, a fim de apresentar as três oportunidades de projeto a qual chegaram. As imagens a seguir mostram uma parte desta apresentação.

\footnotetext{
${ }^{5}$ Ferramenta online de construção de mapas mentais, diagramas e quadros para a construção de ideias colaborativas.
} 
Figura 4: Síntese visual através de gráficos. Fonte: Imagem retirada da apresentação do grupo 4.
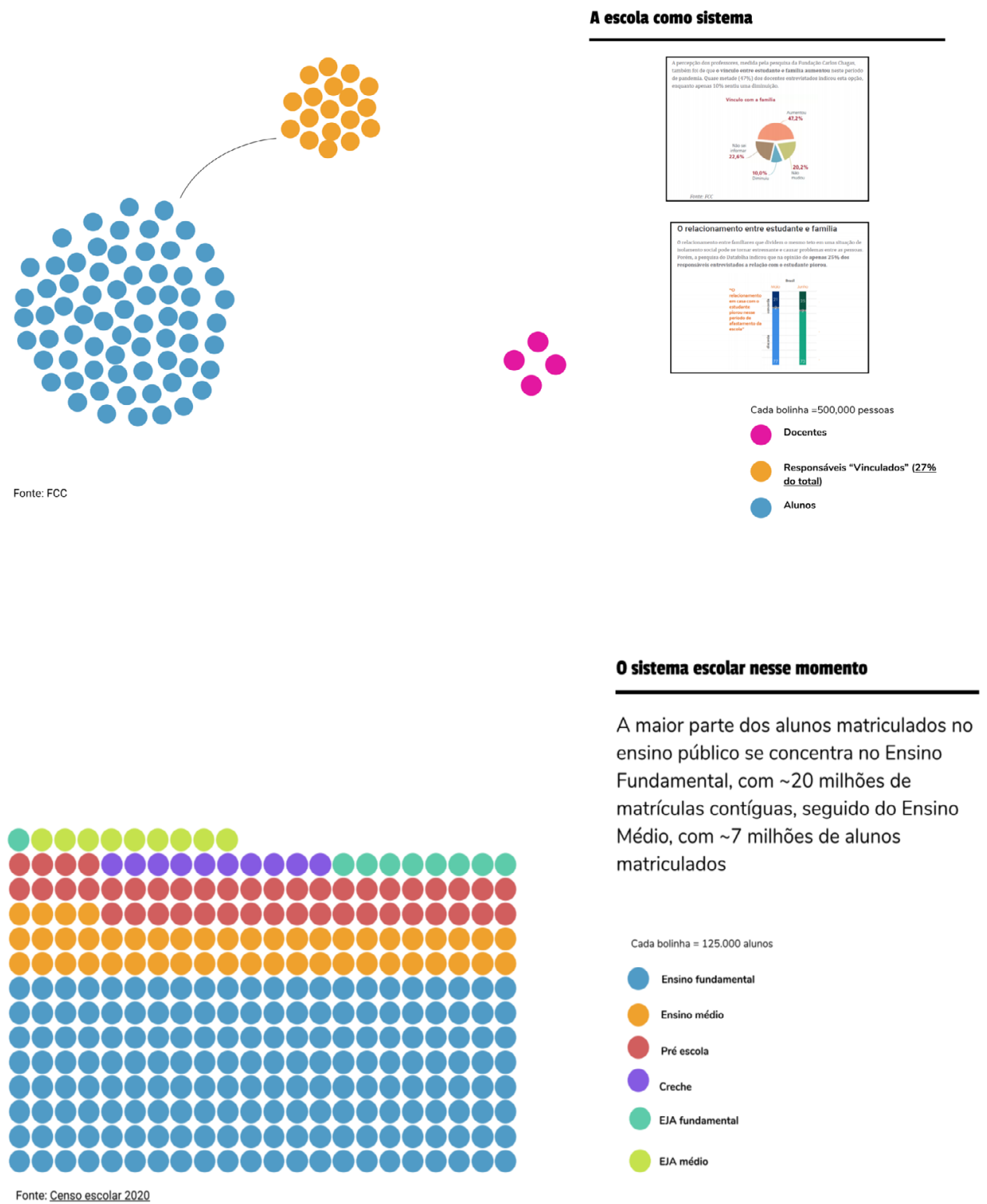

O grupo 6, iniciou a pesquisa fazendo anotações individuais de cada integrante sobre os depoimentos das professoras e, posteriormente, fizeram uma reunião virtual para a execução de um brainstorming ${ }^{6}$ de possibilidades de pesquisa, unindo experiências dos próprios integrantes. Para organizar e registrar os pensamentos construídos, utilizaram o Google Docs e

\footnotetext{
${ }^{6}$ Brainstorming ou Toró/tempestade de Ideias é uma técnica utilizada em dinâmicas de grupo, que tem o objetivo de explorar as habilidades, potencialidades e criatividade dos integrantes, colocando-a a serviço de um determinado objetivo. A técnica se resume a sugerir qualquer pensamento ou ideia que vier à mente a respeito do tema tratado, para reunir o maior número possível de ideias até se chegar em um denominador comum e eficaz para solucionar problemas.
} 
para sintetizar as informações de forma visual, utilizaram o Figma $^{7}$, separando as informações em dois grupos principais: assuntos que o grupo achou mais relevante e as problematizações a respeito das questões levantadas — o que serviu como guia para auxiliar as pesquisas futuras.

Em sequência, ainda utilizando a plataforma Figma, dividiram o espaço de trabalho em cinco quadrantes - um para cada membro do grupo - , a fim de produzirem livremente e explorarem questões próprias. Posteriormente foram realizadas chamadas virtuais para organização e, a partir dessa etapa, o grupo fixou o interesse em trabalhar no campo específico do EJA. Com o objetivo de analisar as problemáticas existentes e os gargalos para se atuar dentro do projeto, iniciaram a pesquisa Desk, dividindo em tópicos os assuntos que se relacionavam.

Figura 5: Pesquisa Desk utilizando a plataforma Figma. Fonte: Imagem retirada da apresentação do grupo 6.

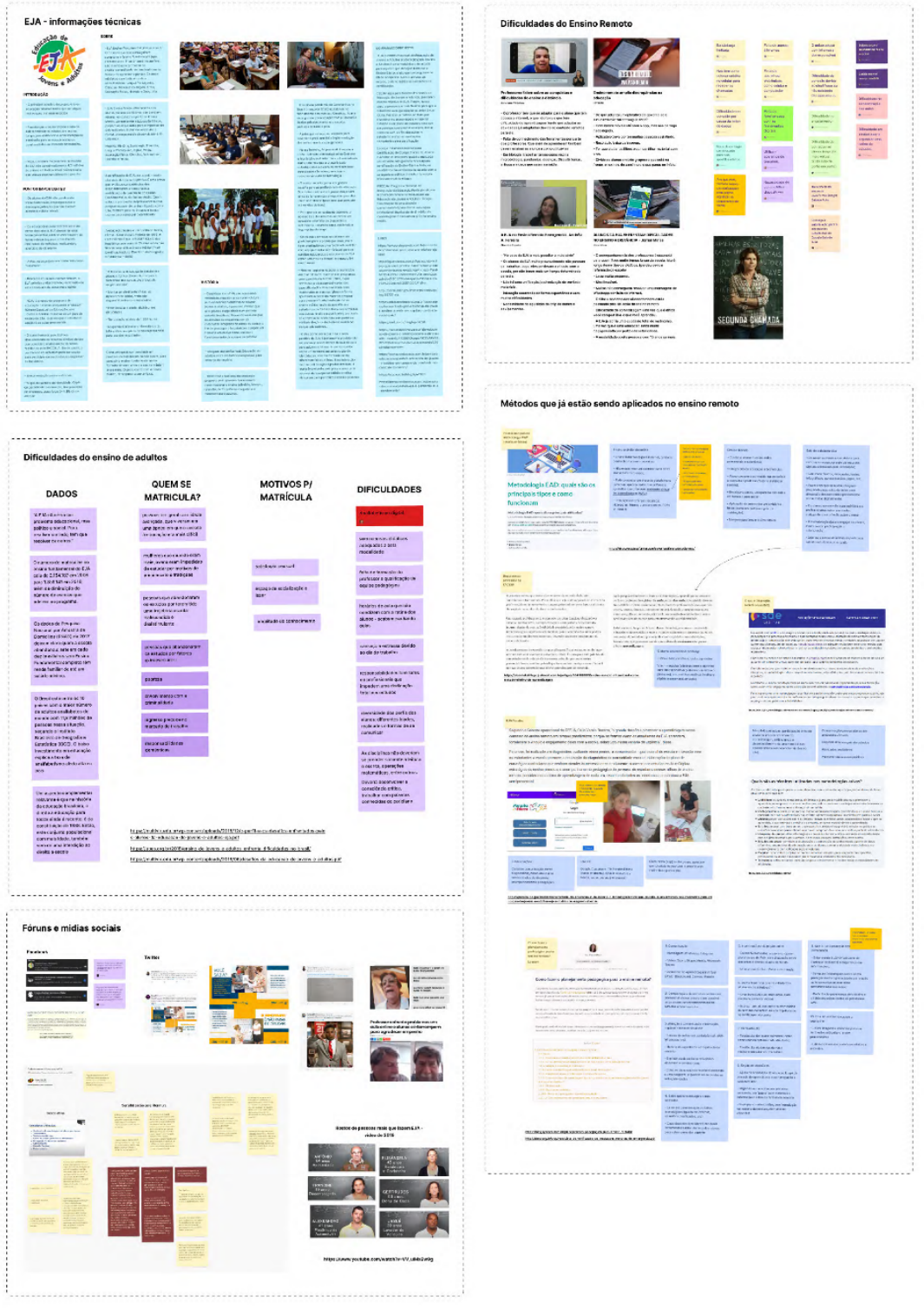

\footnotetext{
${ }^{7}$ Software focado no desenvolvimento de sistemas de design gráfico, prototipagem de interface gráfica de usuário e desenvolvimento de UI/UX, permitindo também o desenvolvimento colaborativo em tempo real com outros usuários remotamente.
} 
Para a ENTREGA 01, o grupo 6 apresentou um esquema de visualização de dados (Figura 6) separado em 3 partes: dados da educação remota, dados do EJA e dados de interseção entre os dois assuntos, e chegou a duas oportunidades de projeto.

Figura 6: Síntese gráfica através de visualização de dados. Fonte: Imagens retiradas da apresentação do grupo 6.
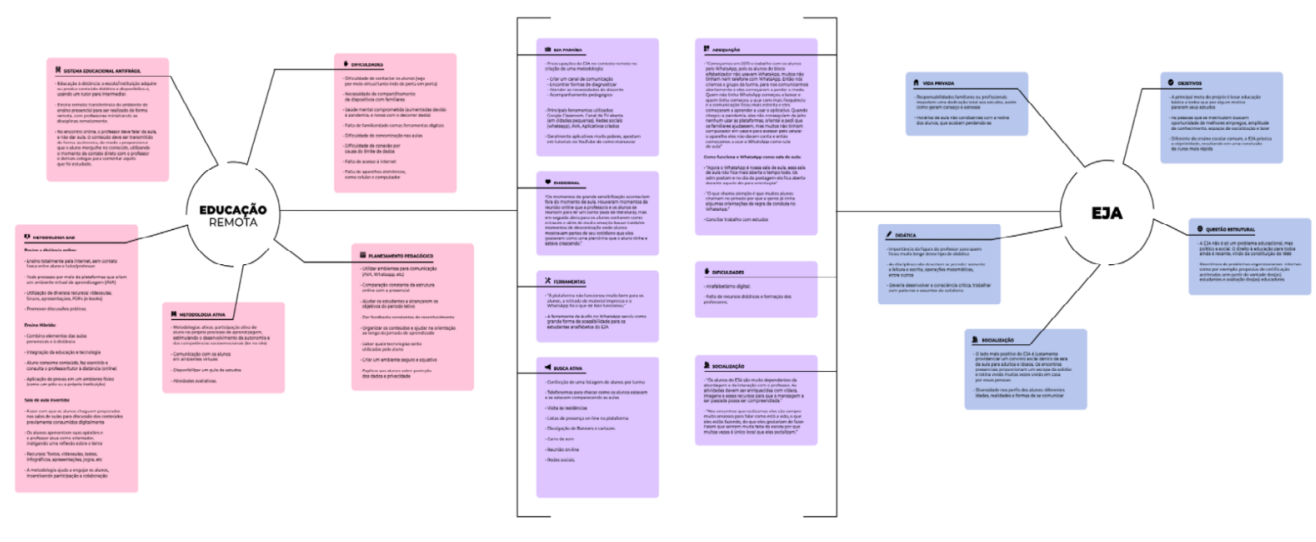

Visualização de Dados - Interseção
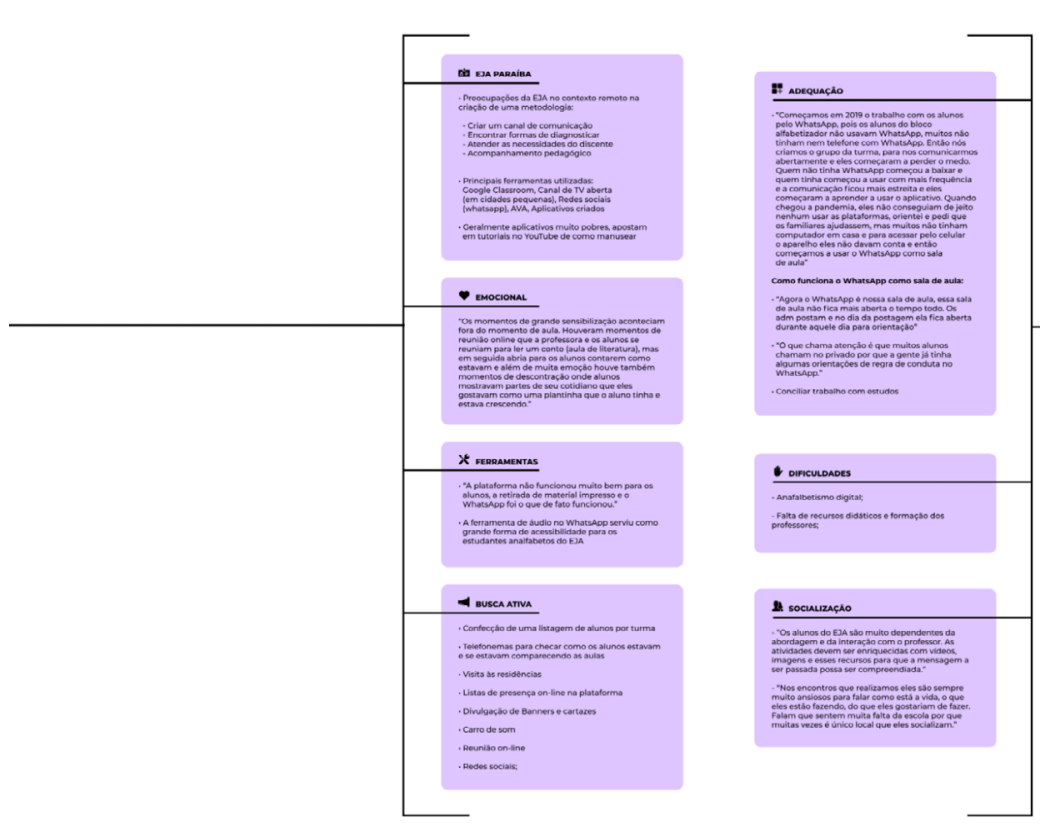


\section{Etapa 02}

A segunda etapa do projeto (ENTREGA 02), com a entrega programada para o dia 14 de abril, consistiu na definição do conceito de projeto, dos caminhos a serem seguidos e do cronograma dos próximos passos. Esta etapa teve duração de 3 semanas, a contar da entrega 01.

Para esta etapa foram apresentadas ferramentas e técnicas com o objetivo de (1) entender o público para qual os alunos estavam projetando - como mapeamento de conceitos; entrevistas estruturadas e semiestruturadas; observação participante e não participante; sonda cultural para mapear experiências; observação dos parceiros por um dia, para melhor entender as rotinas e atividades típicas para quem se projeta; provótipo $^{8}$, para provocar reações no público; e plano de pesquisa - e de (2) síntese e geração de ideias - como análise de entrevistas; personas; pirâmide de sacadas ou insights; parâmetros de projeto; jornada do usuário; e blueprint.

A entrega foi uma apresentação também em slides, contendo o processo de pesquisa referente à etapa e as ferramentas utilizadas, as definições dos conceitos de projeto e o cronograma, porém dessa vez não houve uma análise anterior, ou seja, os professores avaliaram a apresentação na hora da aula síncrona. Os critérios de avaliação foram: pertinência do uso de ferramentas, apreciação crítica, síntese gráfica, elaboração dos objetivos e parâmetros e planejamento dos próximos passos. Com o objetivo de exemplificar o uso das ferramentas e do pensamento projetual desta etapa, foram descritos abaixo os processos de projeto dos grupos 3 e 6 , que obtiveram as melhores avaliações na etapa.

O grupo 3 iniciou a etapa fazendo um mapa mental a partir dos relatos das parceiras com o objetivo de identificar as semelhanças entre eles a fim de detectar quais os problemas em comum e como eles afetam as professoras. Paralelamente, fizeram uma parede de pesquisa, buscando informações secundárias acerca dos problemas levantados e uma síntese visual utilizando os dados das duas técnicas para obterem um panorama geral. Com isso, puderam ver quais temas se destacaram e quais oportunidades seriam possíveis de trabalhar.

Para sanar possíveis suposições e dúvidas levantadas ao longo do processo e para consolidar as oportunidades, fizeram uma entrevista com as duas parceiras com as quais decidiram trabalhar e novamente fizeram um mapa mental para entender e relacionar as diferenças e semelhanças entre os dados coletados. A partir daí, fizeram cartões de insight com o objetivo de destacar as principais falas e momentos durante a análise dessas pesquisas.

Com esse processo, conseguiram definir uma oportunidade e um objetivo claros e assim, desenvolveram possibilidades de caminho a serem seguidos e prototipados na próxima etapa.

O grupo 6 começou a etapa utilizando a ferramenta de usuários extremos, com o objetivo de entender quem são os alunos em condições favoráveis e quem são os alunos em condições desfavoráveis. A partir daí, fizeram um planejamento de pesquisa com suposições, perguntas, possíveis pessoas para entrevistar e as ferramentas a serem utilizadas.

\footnotetext{
${ }^{8}$ Provótipos são parecidos com protótipos porém com a diferença de que são rascunhos de soluções não realistas, que podem provocar discussões com usuários, tomadores de decisão e outros atores relevantes em questão. Assim, Provótipos ajudam a articular algumas das questões que usuários acham difícil descrever em palavras.
} 
A partir das suposições feitas, deram início ao próximo passo da pesquisa - entrevista com a professora parceira -, e formularam 4 hipóteses que serviriam de base para a elaboração de um roteiro de entrevista. O grupo organizou um quadro com os assuntos a serem abordados, as perguntas em si e os objetivos delas, a fim de se prepararem para a entrevista. $\mathrm{O}$ documento final que foi utilizado no momento da entrevista continha uma introdução, um termo de consentimento, as perguntas e os objetivos de cada uma para que não perdessem nenhuma informação relevante.

Para organizar e entender as informações obtidas, o grupo criou 85 cartões de insight, com falas e trechos retirados da entrevista, que foram agrupados em 12 subtemas para uma melhor análise e assim, conseguiram chegar a uma oportunidade e um objetivo claros e parâmetros de pesquisa bem definidos.

\section{Etapa 03}

A terceira etapa do projeto (ENTREGA 03), com a entrega programada para o dia 5 de maio, foi uma apresentação das alternativas geradas e dos resultados dos testes (prototipação e validação). Esta etapa teve duração de 3 semanas, a contar da entrega 02.

Para esta etapa foram apresentadas ferramentas, técnicas e exemplos com o objetivo de idear possíveis soluções para as questões do projeto e selecionar o que faz sentido prototipar - como brainstorming/toró de ideias, brainwriting, swap, barômetro, jornada de futuro, votação do ponto, matriz de priorização entre outros -, e exemplos de prototipação e de testes de protótipos.

A dinâmica da entrega 03 foi similar à 02 , no qual os grupos fizeram uma apresentação em slides, de forma síncrona, por 10 minutos e, posteriormente, os professores fizeram comentários a partir do desenvolvimento mostrado. Os critérios de avaliação foram coerência das soluções propostas para o parceiro, viabilidade das soluções propostas, definição do teste, apreciação crítica e síntese gráfica.

Para exemplificar a etapa, serão descritos aqui os processos dos grupos que se destacaram na etapa - grupos 1 e 6 .

O grupo 1 deu início à etapa 03 fazendo uma avaliação do projeto até o momento, levando em conta a oportunidade de projeto, o objetivo e os parâmetros a fim de chegar a um ponto de partida. Dessa forma, definiram um escopo e partiram para a geração de ideias através de um brainstorming. Com as ideias principais selecionadas, fizeram uma reunião com a professora parceira para entender o que seria possível ou não de pôr em prática e assim, definiram o caminho do produto final, chegando à conclusão de que seriam produzidos dois protótipos da ideia final para que pudessem testar qual seria o mais adequado às necessidades da parceira.

A produção dos protótipos levou em consideração não só os dados obtidos na pesquisa, como também os comentários dos entrevistados ao longo do processo e as observações da parceira. Para o teste, geraram questionamentos que precisariam ser levados em conta (CV coisas a validar) e utilizaram o GoogleMeet para realizá-lo. O teste consistiu em entregar para a 
professora o protótipo e, enquanto ela o testava, o grupo anotava os comentários e reações. O primeiro teste do protótipo teve um resultado satisfatório, necessitando apenas de alguns ajustes.

O grupo 06 iniciou a etapa reformulando os objetivos do projeto e em seguida, partiram para a geração de ideias utilizando a ferramenta de brainwriting, no qual cada membro do grupo pôde complementar a ideia dos demais. No fim do exercício, anotaram os pontos mais interessantes de cada ideia e fizeram uma análise em conjunto, selecionando as mais interessantes e organizando-as em tópicos para facilitar a visualização. A partir daí, fizeram um protótipo do produto final para que fosse testado pela professora.

Durante a elaboração do protótipo, algumas dúvidas e especulações surgiram e foram transformadas em hipóteses a serem validadas durante o teste de prototipagem, através da plataforma GoogleMeet. O teste foi de extrema importância para o grupo pois evidenciou diferentes falhas, acertos e sugestões, além de certas dúvidas por parte da parceira. Dessa forma, puderam fazer melhorias no protótipo já encaminhando o projeto para a etapa final.

\section{Etapa final}

A entrega final consistiu em um vídeo de 3 minutos e um relatório completo sobre os processos projetuais. Nesta etapa não houve apresentações de ferramentas, uma vez que os alunos já estavam nas retas finais. O objetivo desta etapa foi finalizar e preparar a apresentação de explicação do projeto como um todo para os professores de disciplina e as professoras parceiras. Vale ressaltar que não era necessário ter um produto finalizado. A proposta da disciplina era avaliar a aplicação das ferramentas e o pensamento crítico sobre cada etapa. Portanto, os exemplos aqui relatados vão até a parte do projeto no qual o tempo da disciplina permitiu. Optou-se, então, por descrever os processos finais dos grupos 1 e 6, uma vez que os resultados de seus projetos eram totalmente aplicáveis, não dependendo de passos adicionais além das melhorias identificadas.

O projeto do grupo 1 era uma proposta de cartilha (em vídeo ou em texto), com o objetivo de auxiliar na produção de vídeo aulas remotas de forma mais interessante, que pudesse instigar a motivação e diálogo da professora com os estudantes. Assim, apropriaram-se de recursos já existentes, como a plataforma Canva ${ }^{9}$, explicitando um tutorial de uso e sugestões de ferramentas disponíveis. Como ainda estavam na etapa de testes de protótipo e validação com a parceira de projeto, organizaram graficamente os resultados em uma tabela a fim de situar com os objetivos.

\footnotetext{
${ }^{9}$ Canva plataforma digital que possui diversos recursos gráficos disponíveis, que permite os usuários a criação de conteúdos visuais.
} 
Figura 7: Tabela de organização de resultados Fonte: Imagem retirada da apresentação do grupo 1.

\begin{tabular}{|c|c|c|c|c|}
\hline & \multirow{2}{*}{ CARTILHA } & \multirow{2}{*}{ VÍDEO TUTORIAL } & \multicolumn{2}{|c|}{ VÍDEO AULA } \\
\hline & & & NPA & $P A$ \\
\hline $1^{\circ}$ TESTE & $\bullet$ & $\odot$ & $\varnothing$ & - \\
\hline Clareza do processo & $\bullet$ & 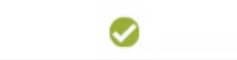 & $\varnothing$ & - \\
\hline Duração do tutorial & $\bullet$ & 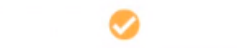 & $\varnothing$ & 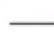 \\
\hline Adequação da linguagem & $\bullet$ & $\bullet$ & $\varnothing$ & \\
\hline Nível de edição do tutorial & - & $\odot$ & $\varnothing$ & 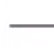 \\
\hline \multicolumn{5}{|l|}{$2^{\circ}$ TESTE } \\
\hline $\begin{array}{l}\text { Identificação das } \\
\text { mudanças }\end{array}$ & $\bullet$ & & & \\
\hline $\begin{array}{l}\text { Agregaram ao conjunto } \\
\text { c/ suporte ao vídeo }\end{array}$ & 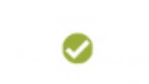 & & & \\
\hline
\end{tabular}

A etapa de validação com estudantes (público-alvo do projeto) com a vídeo aula não ocorreu devido a dificuldades que a professora teve para ajudar a testar. Assim, o grupo optou por prosseguir focando no aprofundamento da cartilha em formato de texto, recebendo retornos da parceira de projeto para ajustar e posteriormente entrar em uma nova fase de provação. Deste modo, o projeto segue para refinamentos específicos para ser futuramente posto em prática pela professora em seu cotidiano de planejamento didático.

O projeto do grupo 6, consistiu na organização e no desenvolvimento de exercícios para o EJA (Educação de Jovens e Adultos), nos quais seriam possíveis de serem aplicados a qualquer matéria, de forma que estimulasse a criatividade e pudesse fortalecer os laços entre estudantes e a professora. O grupo utilizou a plataforma Figma para organizar os materiais, a fim de entender os pontos a serem exaltados nas atividades. Dessa forma, não focaram na quantidade de exercícios para se propor, mas sim na qualidade destes dentro da proposta de projeto, resultando em uma abordagem mais personalizada para a situação específica da professora parceira. $\mathrm{O}$ grupo buscou também artigos, matérias, entre outras fontes, para argumentar e embasar a escolha dos exercícios.

O próximo passo foi a prototipação destas atividades para realizar os testes pela professora parceira, de forma que posteriormente fosse possível realizar ajustes para melhorias pontuais.

\section{Considerações finais}

A experiência de desenvolver o projeto trouxe contribuições valiosas a todos os envolvidos: alunos da graduação em design puderam pôr em prática o exercício de trabalho com clientes reais que apresentaram demandas complexas por conta das dificuldades circunstanciais agudas. Eles estiveram em contato sistemático com as professoras e puderam desenvolver importantes 
habilidades de trabalho: escuta atenta e tradução crítica de ideias, adaptação às frustrações por conta dos sucessivos reenquadramentos de problema, síntese e prototipação de ideias, práticas de negociação da solução e validação da mesma junto às professoras. Por outro aspecto, as professoras envolvidas puderam acompanhar e entender as contribuições que uma intervenção de design pode oferecer aos desafios enfrentados no cotidiano escolar. Em especial, estas docentes puderam comprovar que, trabalhando em conjunto com designers, é possível elaborar de abordagens viáveis que ofereçam contribuições às fragilidades ainda mais evidentes da educação pública.

Além disso, para além das considerações de aprendizado por ambos os lados do projeto, é necessário destacar que a utilização de ferramentas foi fundamental para que os alunos pudessem ter uma visualização de dados mais completa e assim, fazer uma análise mais rica sobre o projeto. Quando se projeta com a ajuda de ferramentas que são coerentes com a especificidade do trabalho, além de fluir melhor, o projeto ainda ganha mais corpo, validade e clareza, uma vez que é possível visualizar cada informação de forma tátil e não apenas no campo das ideias - o que ficou evidente neste projeto cujos objetos de trabalho eram tão abstratos. É válido ressaltar, também, que não só o processo foi mais rico, como também as apresentações, uma vez que os alunos puderam mostrar exatamente o que fizeram, assim como suas escolhas e caminhos seguidos.

\section{Agradecimento}

Escrever este artigo só foi possível por conta da contribuição dos professores e alunos da disciplina aqui descrita - Beatriz Ferreira e Lucas Nonno (professores) e Alice London, Amora Moreira, Angelica Silva, Antonia Motta, Augusto V, Bruno Machado, Clara Brandão, Dalila Rodrigues, Daniel Machado, Danielle Telles, Davi Fernandes, Felipe Loureiro, Helena Belay, Igor Chaves, João Gallas, Josenildo do Nascimento, Júlia Martins, Laiza Pimentel, Lara Rotenberg, Larissa Lima, Laura Policarpo, Lázaro Mendes, Leonardo Furquim, Licia Lima, Lucas Machado, Lucas Vieira, Luiza Conceição, Marina Scalabrin, Miguel Sarzeda, Nina Costa, Rafaelle Silva, Renato Oliveira, Theodoro Boclin, Thierre Campos e Thomas Oughton (alunos), além das 5 professoras parceiras, que cederam seu tempo e disponibilidade para estar em contato com os alunos. O presente trabalho foi realizado com apoio da FAPERJ - Fundação Carlos Chagas Filho de Amparo à Pesquisa do Estado do Rio de Janeiro - Brasil, por meio do Auxílio Recém Contratado - ARC/FAPERJ.

\section{Referências}

Buzan, T. (2002). Mapas Mentais e sua elaboração: um sistema definitivo de pensamento que transformará a sua vida. São Paulo: Cultrix.

Cardoso, R. (2011). Design para um mundo complexo (1ª ed.). São Paulo, SP, Brasil: UBU. 
ENSP/Fiocruz. (13 de maio de 2020). www.portal.fiocruz.br. Acesso em 02 de maio de 2021, disponível em Fiocruz: https://portal.fiocruz.br/noticia/desigualdade-social-e-economica-emtempos-de-covid-19

G1. (25 de Abril de 2021). www.g1.globo.com. Acesso em 02 de Maio de 2021, disponível em G1: https://g1.globo.com/bemestar/coronavirus/noticia/2021/04/25/covid-19-ja-matou-maisbrasileiros-em-4-meses-de-2021-do-que-em-todo-ano-de-2020.ghtml

MindLab. (2019). Métodos Mindlab - Ferramentas de Design Thinking do Laboratório de Inovação da Dinamarca. Escola Nacional de Administração Pública (Enap).

Pimentel, M. (23 de maio de 2020). www.horizontes.sbc.org.br. Acesso em 02 de maio de 2021, disponível em SBC Horizontes:

http://horizontes.sbc.org.br/index.php/2020/05/principios-educacao-online/

\section{Sobre as autoras}

Justine Noronha Hack, ESDI/UERJ, Brasil <juhack92@gmail.com>

Raquel Leal Cunha Cruz Pereira, ESDI/UERJ, Brasil <raquel.Iccp@gmail.com>

Bianca Martins, Dra., PUC-Rio, Brasil <maildabia@gmail.com> 